\title{
The Perfect Bikini Body: Can We All Really Have It? Loving Gaze as an Anti-Oppressive Beauty Ideal
}

\author{
Forthcoming in Thought: A Journal of Philosophy \\ (please cite the final version)
}

\begin{abstract}
In this paper I ask whether there is a defensible philosophical view according to which every body is beautiful. I review two purely aesthetical versions of this claim. The No Standards View claims that every body is maximally and equally beautiful. The Multiple Standards View encourages us to widen our standards of beauty. I argue that both approaches are problematic. The former fails to be aspirational and empowering, while the latter fails to be sufficiently inclusive. I conclude by presenting a hybrid ethical-aesthetical view according to which everybody is beautiful in the sense that every body can be perceived through a loving gaze (with the exception of evil individuals who are wholly unworthy of love). I show that this view is inclusive, aspirational and empowering, and authentically aesthetical.
\end{abstract}

As soon as the summer season approaches, the internet is inundated with articles and slideshows with such titles as: "37 Totally Perfect Bikini Bodies. Rule No.1: there are no rules" or "9 Stunning Bodies That Shatter Society's Stereotypes About the 'Perfect' Body".2 These popular articles are ultimately grounded in the feminist imperative of dismantling sexist and oppressive aesthetic norms that harm women ${ }^{3}$ in a myriad of ways, among which: damaging their self-esteem and affecting their psychological and physical health, exposing

\footnotetext{
${ }^{1}$ https://www.buzzfeed.com/kirstenking/all-your-perfectimperfections?utm_term=.aoxkvwvz2\#.qwJzDJD9G Last accessed on 02/16/2017.

2 https:// mic.com/articles/108394/9-sexy-girls-in-swimsuits-proving-how-fatkinis-are-reinventing-the-bikinibody\#.MsTnXo4x0 Last accessed on 02/16/2017.

${ }^{3}$ In this paper I focus on the Western context, because it is the one I know best, and I focus on women, because it seems to me that on average women of all color, ability, sexual orientation and class are more harmed by conventional standards of beauty than their male counterparts. This focus, however, should not be interpreted as implying that non-Western women, or men from everywhere, are not harmed by current prevailing aesthetic ideals.
} 
them to discrimination in the professional and romantic sphere, and objectifying them and reducing their value to their outward appearance.

There are at least three different ways of interpreting this feminist imperative. The most extreme is a form of aesthetic nibilism, which prescribes that we abnegate aesthetic evaluations of each other. ${ }^{4}$ According to this view, what we really mean by "everybody is beautiful" turns out to be, paradoxically, that nobody is.

While this is a defensible position in the debate about how we ought to aesthetically assess one another's body, it does not seem to be a plausible interpretation of the kind of ideal that is implicitly endorsed in these articles. Here I cannot provide detailed textual evidence, but I submit that they all aim to encourage readers to appreciate some sort of aesthetic value that lies in human bodies. Far from abstaining from judgment, they enthusiastically and vocally present the portrayed women as beautiful.

But a separate and more interesting question is whether aesthetic nihilism is a view worth defending. My answer here is more tentative. Beauty is a fundamental human value, and reserving aesthetic assessment only for objects or animals would entail a great loss: don't we want to meaningfully proclaim that our beloved partners or children are beautiful? Furthermore, we are psychologically prone to making these assessments: it is very unlikely that we could ever teach ourselves not to, and I am wary of ideals that go against our ingrained psychological propensities.

Thus, in this paper I will focus on two other interpretations of the anti-oppressive imperative that is behind these popular articles. A more radical one-call it the No Standards View — states that everybody is beautiful, and thus it eliminates appeal to any specific

\footnotetext{
${ }^{4}$ I thank an anonymous reviewer for suggesting this interpretation.
} 
standard of beauty. A more moderate one-call it the Multiple Standards View_encourages us to widen our standards of beauty. I argue that both approaches are problematic.

The No Standards View is problematic insofar as it preserves maximal inclusivity at the cost of being insufficiently aspirational and empowering. I argue that beauty is a positional good: if everybody were equally beautiful, we would stop caring about beauty.

The Multiple Standards View is problematic for the opposite reason: it preserves the aspirational and empowering character that we want for an ideal, but only for some women — those who qualify as beautiful—thus losing its ethical, anti-oppressive impetus. My solution is that an anti-oppressive ideal of beauty cannot be purely aesthetical, but needs to incorporate some ethical elements. I draw from the experience of loving a person: when we love someone, our very perceptions change: we see them, literally, in a different way from other people. When we say that everybody is beautiful, we mean that, insofar as everybody is potentially lovable, everybody can be looked at with a loving gaze. The Loving Gaze view succeeds in differentiating some people from others: the more beautiful we are inside, the more beautiful we will appear outside. At the same time, the discriminating criterion is not based on morally irrelevant and oppressive features. Therefore, the Loving Gaze view is superior to both the No Standards and the Multiple Standards View because it is both inclusive and aspirational, while remaining genuinely, if not exclusively, aesthetical. 


\section{No Standards View}

Suppose that we embrace the idea that, in order to have a perfect bikini body, you just need to have a body and wear a bikini, ${ }^{5}$ because every body is maximally, and thus equally, beautiful as it is. ${ }^{6}$ What kind of aesthetic ideal lies behind this claim?

Sherri Irvin has recently proposed a sophisticated articulation of this view (Irvin, MS). Irvin starts by reviewing the overwhelming evidence of harm inflicted by conventional standards of beauty to those who fail to satisfy them. She then argues that we have ethical reasons to reject those aesthetic standards and look for alternative ones. She proposes an original model of aesthetic practice that she calls aesthetic exploration. In short, aesthetic exploration involves two dispositions: a tendency to approach an object carefully seeking it out its aesthetic affordances with the specific intent of finding pleasure in them, and a tendency to do so with a sense of curiosity and adventure, "a willingness to encounter and celebrate the unique and surprising, a willingness to tolerate and persist through moments of experience that are jarring" (Irvin MS, 16). Qua practice, aesthetic exploration can be intentionally cultivated and pursued, thus falling under the honorable tradition of exercising indirect control over attitudes that may be implicit and thus escape voluntary direct control. ${ }^{7}$

\footnotetext{
${ }^{5}$ I am grateful to Natalie Ashton for noticing that this specific phrase suggests an alternative interpretation of the "perfect bikini body" idea: everyone has a right to be comfortable on the beach and wear what they want, independently from what they look like, and from what onlookers think or feel. I agree this is one position present in the debate, and it is worth keeping it in mind. However, the slideshows and articles linked above make it clear that they are presenting an alternative aesthetics, either one according to which "we are all beautiful" and "beauty knows no boundaries", or one according to which fat bodies can be stunning. My argument concerns these aesthetic ideals.

${ }^{6}$ A second, less extreme, variant of the view is that every body, qua human body, surpasses a certain threshold and qualifies as beautiful, but, after that, one body can be more or less beautiful than others. I consider this second variant at the end of the section. I am indebted to an anonymous reviewer for prompting me to clarify this point.

7 There is a growing literature in moral psychology dedicated to this topic. In aesthetics, Anne Eaton defends an analogous approach in the more restricted context of negative attitude toward fat bodies. In (Eaton 2016), she pursues an explicitly Aristotelian strategy of changing one's taste via habituation and imaginative engagement with representations.
} 
Everybody is beautiful, according to Irvin, insofar as "living human bodies, all of them, do have very rich affordances by virtue of their colors, textures, ever-shifting forms, complex structures, capacities for movement, and so forth. The human body - every human body - is an incredibly replete aesthetic object" (op. cit. 21). Thus, "all bodies can afford positive aesthetic experiences if approached through an appropriate appreciative practice" (cit. 29).

Irvin's view is very appealing, and it encourages us to engage in an enriching activity. But can it function as the feminist ideal of bodily beauty that we are looking for? I worry that the very strength of this view, its inclusivity, is also its major weakness: according to this view, nobody can fail short of the ideal, provided they are gazed at in the appropriate way. Assume for the time being that this is desirable. Is this view as aspirational and empowering as the ideal we are looking for? I am afraid not.

First, insofar as the view asserts that everybody is maximally, and thus equally beautiful, we lose the aspirational nature of the ideal. This is why I called it "No Standards" view, as opposed to "One-Maximally-Met-Standard" view: when everybody meets the standard, there is no need to appeal to it, because it does no work of weeding the nonbeautiful from the beautiful. Thus, the standard itself recedes in the background, becoming obsolete or invisible. To see what I mean, consider the following example concerning a standard of conventional beauty.

Straight teeth used to be a mark of beauty. But in contemporary US upper-middle classes children commonly wear braces even when not medically necessary, for purely aesthetic reasons. Similarly, teeth whitening is increasingly common amongst those who can afford it, and is virtually obligatory for actors, politicians, TV hosts, and so forth. In those contexts, having straight, white teeth has lost its character of positive aesthetic feature, as 
something that people get complimented on, and has become as aesthetically unremarkable as having two arms. ${ }^{8}$

One could object, however, that even though the No Standards view fails to discriminate between human bodies, it still succeeds in differentiating human bodies from other objects. Consider a pile of excrement: barring unusual circumstances, such as an art exhibit, that could count as an objectively ugly thing. Or maybe it could differentiate human beings from non-human beings, such as animals, or possibly aliens. Beauty would then be like Kantian dignity: every human being, just in virtue of being human, has dignity. Analogously, maybe every human being, in virtue of being embodied, is maximally and equally beautiful, and its positive aesthetic value differentiates human beings qua objects from other, non-human objects or beings.

While this is a plausible conclusion, it is very unexciting: "Every body is beautiful! Not like those tentacled monsters from Venus! And much prettier than a pile of dung!"-it doesn't quite have the right ring to it.

Jokes aside, the view does not provide us with the means to make meaningful aesthetic comparisons between human bodies. As a consequence, it does not provide us with a target we should strive to attain. So while it describes something of value, it is epistemically and practically inert.

As unexciting as this ideal sounds, maybe this is what we want after all: maybe it is desirable precisely because it is not aspirational, thus removing the need for competition that pits women (and sometimes also men) one against the other.

However, I worry that the view also fails to be empowering.

\footnotetext{
${ }^{8}$ Both features still function well as markers of socio-economic class, and remain standards of aesthetic appreciation in contexts where cosmetic dental enhancements are not readily available or widespread.
} 
It is a psychological fact of human nature that we care about being beautiful because it sets us apart from others: it makes us more appealing than our competitors as sexual and romantic partners or as job candidates (whether beauty is relevant to the job or not), and it renders us worthy objects of admiration, emulation and honor. After all, it is these very facts that make the current beauty ideals so harmful to women (and men). Those who are perceived as ugly, where that means uglier than others, fare less well on the romantic and sexual “market”, get fewer jobs and promotions, have lower self-esteem, and so forth. ${ }^{9}$ If everybody were all equally beautiful, we would come to care a lot less about beauty.

To put it in other terms, bodily beauty, differently from goods such as dignity, health, or virtue, is a positional good, meaning that its absolute value depends on the possessor's place in the distribution of the good. ${ }^{10}$ If we were all beautiful, beauty would not be as valuable.

Consider the case of white and straight teeth again. Its aesthetic value among wealthy, upper-middle class individuals has greatly diminished, since it is not a mark of distinction anymore. In fact, in recent years having a small flaw in the context of overall nice teeth (such as gap between the upper incisors, or a mildly broken tooth) has come to be considered a sign of beauty and sexiness, and it seems plausible to me that it is because those quirky, minor imperfections break the boredom of perfect teeth in a sea of equally perfect teeth.

One way to counteract the loss of positionality connected to the No Standards View is to reject the idea that "every body is beautiful" implies that every body is maximally, thus equally, beautiful. That is, one could claim that every body has some beauty, but it still possible

\footnotetext{
${ }^{9}$ See Langlois et al. 2000, and Hosada et al. 2003.

${ }^{10}$ See Brighouse and Swift 2006, p. 472.
} 
to rank people according to degree of beauty. However, this less radical variant of the view is unstable: in order to clarify how we can differentiate between beautiful and more beautiful, either we resort to conventional standards, which we already deemed problematic, or the view collapses into the Multiple Standards View (which I consider next).

To conclude: the No Standards View, when interpreted to mean that everybody is maximally and equally beautiful, cannot function as the aspirational, empowering ideal that we were looking for, notwithstanding its rhetorical efficacy. ${ }^{11}$

\section{Multiple Standards View}

Should we then endorse the Multiple Standards View? At first, it might seem that that is what the supporters of the No Standards View aimed at all along: what they ultimately care is that women stop trying to conform to standards that are excessively narrow and often impossible to obtain, and shaped by oppressive, demeaning norms.

But once we start looking for more inclusive standards, another worry arises: where do we draw the line between the beautiful and the non-beautiful? Let us analyze a few options, starting with "size", which is one of the most important issues in the feminist debate. Someone might argue that, while fat women are beautiful, very obese ones are not. But we have evidence showing that obese people are greatly harmed by conventional ideals of beauty that deem them as 'disgusting', and they are discriminated against in many other

\footnotetext{
11 The No Standards View might lead one to conclude that achieving physical beauty is not important, and that we should look for empowerment in other domains. While this is an option worth considering, and to some extent one I share, it does not seem to me that this is what advocates of the view, such as Irvin, have in mind. I thank an anonymous reviewer for prompting me to consider this possibility.
} 
settings. ${ }^{12}$ Therefore, we have ethical reasons to resist the suggestion that obese people are ugly just in virtue of their obesity.

Once could appeal to health reasons: some bodies are ugly because they are unhealthy, abnormal. Irvin has a convincing response to this suggestion: first, why would we want to socially penalize someone who suffers from a health condition, which is likely to already be distressful to them? Second, observers are not in a good position to know the underlying health condition of someone else's body (Irvin MS, 25).

There is a further problem with this line of thought: it relies on conceptions of normality and health that are problematic according to an anti-ableist, or disability-positive, perspective. Such a perspective denies that disability is intrinsically bad for the disabled person. Without endorsing the notion that disability is intrinsically good for a person, it is often committed to claims such as the following:

“(a) Disability is analogous to features like sexuality, gender, ethnicity, and race.

(b) Disability is not a defect or departure from "normal functioning."

(c) Disability is a valuable part of human diversity that should be celebrated and preserved.

(d) A principal source of the bad effects of disability is society's treatment of disabled people, rather than disability itself." (Barnes 2014, 93)

Within this framework we find the idea that disabled, thus conventionally "unhealthy" and "dysfunctional" bodies, can be, and in fact have been throughout the history of art, sources of beauty. In Tobin Siebers' words:

\footnotetext{
12 The empirical research on anti-fat prejudice is very extensive. O’Brien et al. 2013, which discusses the relationship between physical appearance concerns, disgust, and anti-fat prejudice, also contains a review of the myriad of studies on anti-fat prejudice (619-620). Eaton 2016 also refers to many of them.
} 
"Disability aesthetics prizes physical and mental difference as a significant value in itself. It does not embrace an aesthetic taste that defines harmony, bodily integrity, and health as standards of beauty. Nor does it support the aversion to disability required by traditional conceptions of human or social perfection. Rather, it drives forward the appreciation of disability found throughout modern and avant-garde art by raising an objection to aesthetic standards and tastes that exclude people with disabilities." (Siebers 2006, 71)

The disability aesthetics perspective may be the most formidable opponent to the Multiple Standards View, making it impossible to draw a line by using any traditional standard of bodily beauty, such as proportionality of limbs, symmetry and so forth. Siebers himself would not seem to endorse a view such that everything is beautiful, since he discusses, for instance, examples of kitsch or bad art. But notwithstanding his emphasis on the ineluctable materiality and bodily nature of art works, he only discusses works of art, and does not articulate a view about beauty of bodies, disabled or able-bodied.

One final possibility would be to draw the line in some unusual place, where it has not been drawn before. Maybe an ugly person is a person who is "too perfect", like those portrayed in the Nazi paintings Siebers discusses as examples of kitschy art. But a person who is naturally too perfect is not at fault for being that way, precisely like those who have many imperfections. Furthermore, it might be too counterintuitive for a theory of beauty to imply that those who are extremely beautiful by conventional standards are in fact ugly, just by virtue of adhering to those conventional standards of beauty.

Maybe someone who has subjected himself to too many cosmetic surgeries, and has become grotesquely artificial, could count as ugly. But this proposal also stigmatizes people unjustly: those who undergo many cosmetic surgeries do so under cultural and societal 
pressure, which in turn depends on those very oppressive norms we started with. And if they end up with a grotesque appearance, then again why would we want to penalize them further?

The Multiple Standards view, then, fails at being sufficiently inclusive, and thus falls short on its ethical motivations. In order to find a satisfying ideal of bodily beauty, we have to look outside of the purely aesthetic domain.

\section{A Loving Gaze as an Ethical Ideal of Beauty}

We often talk of internal beauty, of being beautiful on the inside. This notion of beauty is metaphorical, but there is a non-metaphorical way in which what is "inside" a person-her character, her spiritual and intellectual qualities_affect her "outside": it affects the way people perceive her.

This is especially evident in loving relationships. Imagine someone who is disgusted by fat people, even though she rationally rejects her disposition. Suppose she happens to befriend an obese person. Her loving relationship will affect not only her emotional responses to this person, but her perceptions as well. While still seeing her as fat, she will cease being disgusted by her, and instead come to see her as beautiful, or at the very least not ugly. ${ }^{13}$ Or imagine someone slowly reciprocating the love of a person previously assessed as unsightly, won over by that person's internal beauty. Moved by her attraction, she will discover valuable aesthetic features of the beloved, and at some point she will look at her or him, and see beauty. Her perceptions have changed, and, to some extent, that change may be permanent. Some luster may go away as the love fades, if it does, but she will never look at

\footnotetext{
${ }^{13}$ I suspect there is a positive correlation between the intensity of the affection and the degree of aesthetic appreciation: the more the person is loved, the more beautiful she appears to the lover.
} 
that person as she used to look at them before loving them. Or think about how we see our children, siblings, parents: our affection makes us go beyond their aging, their physical flaws, their imperfections. Every loving parent sees their infant as the most perfect creature on earth, even when bystanders (secretly) beg to differ. ${ }^{14}$

An attractive interpretation of "everybody is beautiful," then, is not a purely aesthetical one in the modern sense, but a hybrid aesthetical-ethical one. What I have in mind is what the ancient Greeks would refer to as kalos kagathos. ${ }^{15}$ This approach rejects a neat distinction between the ethical and the aesthetical that is commonplace in modern philosophy.

The particular ethical element that I want to incorporate is that of a loving gaze. When we say that every body is beautiful, we mean that any body can be an appropriate object of a loving gaze. According to what I call the Loving Gaze view, the most beautiful individuals are the most lovable ones, independently of what they look like from the outside. Some notso-lovable individuals will retain some degree of beauty, because they are still appropriate object of love from the perspective of some people (for instance, their mothers) but will not be very beautiful, even if they look good from the perspective of conventional standards. Finally, others may be so underserving of love that those who can look inside them will see them as utterly ugly. For example, consider Patrick Bateman, the protagonist of the novel American Psycho, by Bret Easton Ellis. Bateman is portrayed as an evil psychopath, who deceives, murders, and tortures his victims in the most sadistic ways. His outward handsomeness, which is a feature intentionally highlighted by Easton Ellis, makes him no

\footnotetext{
14 The TV show Seinfeld provides an amusing illustration of this phenomenon: https://www.youtube.com/watch?v=rkadtxlCRU4

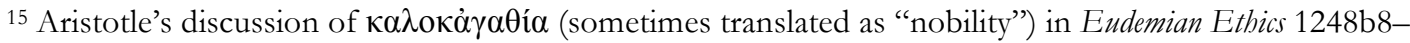
1249a17 might be the most famous philosophical discussion. I thank an anonymous reviewer for kindly providing this reference.
} 
less aesthetically repellent-if anything, more, in the same way in which the perfection depicted in Nazi paintings look to the knowledgeable viewer not just kitschy, but horrifying.

The Loving Gaze view, then, retains positionality without losing its ethical impetus: some individuals are more beautiful than others, but the hierarchy is not determined by morally irrelevant or, worse, unethical features. Those who are most beautiful on the inside are also the most beautiful on the outside.

At this point, one might worry that I am changing the subject. Isn't there something like sheer non-ethical beauty? ${ }^{16}$ Fully addressing this worry would require me to tackle the much broader, and fervently debated, issue of the relation between ethics and aesthetics, which goes beyond the scope of this paper. Clearly, my view belongs to the tradition of aesthetic moralism, according to which an object's aesthetic value is directly connected with its ethical value. ${ }^{17}$

However, there are a few ways in which my view differs from many views that belong to that tradition. First of all, the Loving Gaze view has a subjectivist streak, due to its relation to the particularism that unavoidably stems from our loving relations: assessing a human body as beautiful need not be a universal, disinterested judgment. At the same time, insofar as thoroughly evil people à la American Psycho (if they really exist) are not worthy of personal love, ${ }^{18}$ they also are objectively ugly. Hence, judgments of physical beauty are not completely subjective either.

Second, and perhaps more importantly, even though the view is not exclusively aesthetical, it is irreducibly and authentically aesthetical. In order to be assessed as beautiful, as

\footnotetext{
${ }^{16} \mathrm{I}$ thank an anonymous reviewer for asking me to address this point.

17 This view is prevalent amongst philosophers of art. The literature on this topic is very extensive. For good reviews, see Eaton 2012 and Kieran 2006.

18 They might still be worthy of God's love, or of being respected qua human beings.
} 
opposed to just good, the object of the loving gaze necessarily requires embodiment. When we love a person we come to appreciate features of their body, not just their mind, that we might have not appreciated or noticed otherwise. Therefore, the loving gaze is not at all metaphorical: it is the real gaze of an actual person, whose perceptions are forever altered by the act of loving, and who sees the beloved body as beautiful.

Notice, however, that none of the above implies that someone like Patrick Bateman is ugly in every possible sense. He is still handsome by conventional standards of attractiveness. In general, it is perfectly coherent to say that someone is conventionally attractive but not really a beautiful person, where beautiful is meant to convey an aesthetical/ethical judgment (kalos kagathos). Of course, with most people there is not going to be such an extreme gap between their conventional beauty and their beauty in this anti-oppressive sense as is the case with fictional evil psychopaths.

Finally, the Loving Gaze view is not a view about how in fact we can aesthetically appreciate everybody: personal preferences may still be at play, as they are in our loving relationships. That everybody is beautiful does not mean that every particular individual will actually see everybody else as beautiful. This is a view about who can be objectively assessed as beautiful. And the answer is: (almost) anyone. ${ }^{19}$

\footnotetext{
${ }^{19}$ I am extremely thankful to: Elizabeth Barnes and Ross Cameron for comments on the abstract from which this paper originated; Pamela Corcoran and Ariela Tubert for conversations at the initial, nebulous stage; Natalie Ashton, Paulina Sliwa, and two anonymous reviewers for written feedback; my commentator Abby Wilkerson and all audience members at the Annual Meeting of the American Society for Aesthetics in Seattle in Fall 2016; and finally Sherri Irvin and Shen-yi Liao for intellectual and emotional support on this project.
} 


\section{References}

Barnes, E., 2014, “Valuing Disability, Causing Disability”, Ethics, 125(1): 88-113.

Brighouse, H., and Swift, A., 2006, "Equality, Priority, and Positional Goods," Ethics, (116)3: $471-497$.

Eaton, A., 2012, "Robust Immoralism," The Journal of Aesthetics and Art Criticism, 70: 281-292.

Eaton, A., 2016, “Bodily Taste and Fat Oppression”, in Irvin (ed.) 2016.

Hosada, M.et al. 2003, “The effects of physical attractiveness on job-related outcomes: A meta-analysis of experimental studies." Personnel Psychology 56.2: 431-462.

Irvin, S., 2016, Body Aesthetics, OUP.

Irvin, S., MS, "Aesthetic Exploration, Social Injustice, and the Body."

Kieran, M., 2006, “Art, Morality and Ethics: On the (Im)Moral Character of Art Works and Inter-Relations to Artistic Value," Philosophy Compass, 1:129-143.

Langlois, J. H., et al. 2000, "Maxims or myths of beauty? A meta-analytic and theoretical review." Psychological bulletin 126.3: 390-423.

O’Brien, Kerry S., et al. 2013, “'The relationship between physical appearance concerns, disgust, and anti-fat prejudice." Body Image 10.4: 619-623.

Siebers, T., 2006, “Disability Aesthetics”, Journal for Cultural and Religious Theory, 7(2): 63-73. 